\title{
Is Mastectomy Oncologically Safer than Breast-Conserving Treatment in Early Breast Cancer?
}

\author{
Fabian Riedel André Hennigs Sarah Hug Benedikt Schaefgen Christof Sohn \\ Florian Schuetz Michael Golatta Jörg Heil
}

Department of Obstetrics and Gynecology, University of Heidelberg, Medical School, Heidelberg, Germany

\section{Keywords \\ Breast cancer - Mastectomy - Surgery - Surgical therapy . Breast-conserving therapy}

\section{Summary}

Aim: To describe and discuss the evidence for oncological safety of different procedures in oncological breast surgery, i.e. breast-conserving treatment versus mastectomy. Methods: Literature review and discussion. Results: Oncological safety in breast cancer surgery has many dimensions. Breast-conserving treatment has been established as the standard surgical procedure for primary breast cancer and fits to the preferences of most breast cancer patients concerning oncological safety and aesthetic outcome. Conclusions: Breast-conserving treatment is safe. Nonetheless, the preferences of the individual patients in their consideration of breast conservation versus mastectomy should be integrated into routine treatment decisions.

(c) 2017 S. Karger GmbH, Freiburg

\section{Past and Recent Developments in Breast Cancer Surgery Concerning Survival and Local Recurrence}

Oncological safety has priority in breast cancer surgery. But what does it mean when we discuss with breast cancer patients different surgical options that have equivalent 'oncological safety' or when we differentiate them from other options that may go along with lower oncological safety? Oncological safety as a collective term imprecisely subsumes many different time-to-event endpoints covering a wide range, from simple survival patterns like overall survival (OS) or specific breast cancer-related relative over- all survival (ROS) to recurrence patterns like the locoregional recurrence (LRR) rate or the distant recurrence rate. In the context of primary breast cancer with OS and ROS rates higher than $90 \%$ over 5 years in unselected cohorts, the usage of surrogate endpoints for OS, such as (distant) disease-free survival, is increasingly common, especially in randomized trials but also in cancer registry outcome analyses [1]. The definitions of several of these endpoints are often imprecisely used; especially endpoints with differing locoregional components have been observed in the comparison of research results [2]. Initiatives to harmonize these definitions were made to facilitate comparisons between trial results by using standardized definitions [3]. Additionally, a further aspect of outcome analyses relates to the evaluation of quality-of-life patterns (or patient-related outcome patterns), which should also be considered in the context of any oncological safety evaluation [4] because they sometimes better reflect the patients' individual perceptions of treatment outcome than abstract survival patterns [5].

These considerations about different definitions of oncological safety patterns lead to another challenge in the specific context of breast cancer surgery. Especially in the concrete evaluation of oncological safety patterns between breast-conserving treatment (BCT) versus mastectomy, the differentiation between OS and LRR might be considered as obsolete because the whole question itself about potential safety differences might sound unfamiliar to many breast surgeons involved in the treatment of patients with primary breast cancer in 2017. The question whether mastectomy is safer than BCT seems to deal with a problem that was solved long ago, with the important impact of Fisher et al. [6, 7] und Veronesi et al. $[8,9]$ more than 25 years ago. Based on their study results, BCT has been established as the standard treatment for most patients with early breast cancer because it can maintain an equivalent oncological safety in comparison to mastectomy. Before this perception, the decision to perform a mastectomy was based, firstly, on the belief that radical surgery of the breast (as modified radical mastectomy, MRM) decreases the LRR rates compared with BCT and, secondly,

\section{KARGER}

(c) 2017 S. Karger GmbH, Freiburg
Prof. Dr. med. Jörg Heil

Department of Obstetrics and Gynecology

University of Heidelberg. Medical School

Im Neuenheimer Feld 440, 69120 Heidelberg, Germany

joerg.heil@ med.uni-heidelberg.de 
that it reduces the uncertainty of annual follow-up mammograms and potential recall for further diagnostic procedures and treatment. BCT consists of breast-conserving surgery (lumpectomy, partial mastectomy) and whole-breast radiotherapy, with the aim to achieve long-term local disease control in conjunction with minimum local morbidity; i.e., the cosmetic outcome is favorable and the side effects of treatment are limited. A meta-analysis of the 10year survival in 7 randomized trials showed equivalence in terms of overall outcome for BCT and mastectomy [10]. It became evident that BCT involved some risk of recurrence in the remaining breast tissue but no significant differences in OS at 10 years [11], confirming these results in a follow-up of 20 years $[12,13]$. All following studies showed that women with early breast cancer who were treated with BCT and postoperative radiotherapy to the ipsilateral breast had higher rates of LRR but similar long-term survival when compared with those undergoing radical mastectomy. Nonetheless, providing local control is still important and has an impact on OS; i.e., local recurrence has been estimated as a risk factor for the development of distant metastases [14]. Higher risk of LRR is associated with higher risk of distant disease and subsequent risk of breast cancer-related death. This estimate may vary substantially with age at diagnosis, axillary lymph node affection, the histological type of the cancer and, according to this, the application and duration of systemic treatment. To limit the negative effect on OS through local recurrence, it is nowadays generally accepted that, for early breast cancer, the LRR rates should be within the limit of $1 \%$ per year or within $10 \%$ at 10 years [15]. Exemplarily for the initial European Organisation for Research and Treatment of Cancer (EORTC) 10801 data after a 10-year follow-up, the LRR rates were $20 \%$ after BCT and $12 \%$ after mastectomy (but no significant difference was identified in long-term OS) [16]. An even longer followup of these patients after more than 20 years confirmed the equivalence in OS without having focused on LRR because the number of events was low in the follow-up since the previous analysis [17].

LRR rates following BCT have fallen considerably over the last 2 decades, as a result of better imaging and more attention to margins. Although local recurrence was considered to be more common after BCT than after mastectomy, it is now almost at comparable low levels, even for aggressive subtypes like triple-negative breast cancer [18]. The convergence of the LRR rates of BCT and mastectomy in recent years was also mainly driven by better systemic treatment options, which in parallel also resulted in improved overall and distant disease-free survival [19]. A growing molecular genetic understanding in the last decade provided a new view on breast cancer as a heterogeneous disease that can be classified into different intrinsic biological subtypes with miscellaneous clinical and pathological features and different therapeutic responsiveness patterns and outcome perspectives [20-23]. This has led to the possibility of individually tailored treatment reducing the impact of local treatment on OS. In this context, particularly the progress in primary systemic therapy in the last decade has led to a rising rate of pathologic complete responses (pCRs) after neoadjuvant chemotherapy [24]. Reaching a pCR goes along with excellent prognosis for specific breast cancer subtypes (i.e. human epidermal growth factor receptor 2 (HER2)-positive and triple-negative subtypes) [25]. These results have opened the door to recent innovative study designs that want to give an answer to the question of whether a surgical approach in the breast is necessary at all after proof of pCR through vacuum biopsy after neoadjuvant chemotherapy [26].

Concerning the impact of systemic therapy in a large study with over 85,000 patients who were treated in trials with chemotherapy and endocrine therapy between 1990 and 2011, the LRR rates decreased from 30 to $15 \%$ without any influence, irrespective of whether BCT or mastectomy was performed. LRR additionally depends on the immunohistochemical subtype, with the triple-negative type having the highest rates and the hormone receptor-positive and HER2-negative types having the lowest rates of LRR [27]. In a representative routine cohort from Germany with over $70 \%$ of the patients treated with BCT, LRR rates of $3.9 \%$ over 5 years were seen [1]. Thus, the rates of breast cancer recurrence after BCT are nowadays similar to the rates of local recurrence seen after mastectomy. However, it has to be stated that the rates are obviously not identical; especially in younger patients, the discrepancy becomes evident $[28,29]$. On the one hand, based on a review of the available literature there is no definitive evidence that mastectomy provides a consistent recurrence-free survival or OS benefit over BCT. On the other hand, BCT patients have a lifelong consistent but small risk of in-breast relapse that is higher than in mastectomy patients.

\section{Impact on Axillary Surgery}

With the beginning of the millennium, surgical radicalness could be further reduced through the implementation of axillary staging via sentinel lymph node dissection (SLND), which showed lower morbidity [30] with equal oncological safety [31]. Thus, the standard histological assessment of a minimum number of axillary lymph nodes after axillary lymph node dissection (ALND) as a staging method for a clinically non-suspect axilla is nowadays obsolete $[32,33]$. The trend of reducing therapeutical morbidity has been a one-way street involving study designs that had a huge impact on everyday treatment decisions in breast units worldwide. For example, the results of the American College of Surgeons Oncology Group (ACOSOG) Z0011 trial could show a similar outcome for patients without axillary completion with 1-2 affected sentinel lymph nodes (SLNs) under specific circumstances (adequate radiotherapy, etc.) [34], and the results from the AMAROS trial ('Mapping of the Axilla: Radiotherapy or Surgery?') yielded similar outcome results between ALND and axillar radiotherapy for patients with positive SLNs [35].

\section{Paradoxical Trend: Rising Rate of Mastectomies}

Even though BCT offers an equivalent option concerning the potential risk of LRR and OS, a rising rate of mastectomies has been observed in the recent years since 2005 [36]. Data from the USA show that, after a stable rate of BCT, a rising rate of mastectomies 
could be seen in the recent decade [37], which is mainly due to an increase of contralateral prophylactic mastectomy (CPM) while the rates for unilateral mastectomy remained stable [19]. Limited data exist from Europe, but they do not show a comparable trend outside the USA [38]. It is a paradox that the increase in CPM happens during a time when most efficient (neoadjuvant) systemic therapies can even reduce the risk of contralateral cancer. This trend towards CPM is mainly driven by personal factors and less by tumor biological factors, i.e. by a greater awareness of the breast cancer risk and the widespread availability of genetic counseling and testing. Also, the availability of advanced and safe options of breast reconstruction after mastectomy has increased in recent years, which may have lowered the threshold to opt for mastectomy in the individual decision-making process [39]. The trend towards CPM is mainly patient driven and is focused on subgroups of younger and well-informed and well-educated patients. Moreover, psychological factors might be relevant [40]. Especially a misperception regarding the safety of BCT versus mastectomy and an overestimation of the risk of contralateral breast cancer development might have contributed to the increase of CPM. Most of the patients with unilateral breast cancer asking for bilateral mastectomy are not at high risk for the development of subsequent breast cancer and overestimate their level of risk for developing breast cancer [41]. The a priori low risk of contralateral cancer development leads to the fact that, with the growing number of CPM, no improvement in survival can be observed [42]. There is no evidence that CPM is associated with lower mortality in breast cancer patients [43]. Nonetheless, in quality-oflife evaluations after CPM, most patients afterwards seem to be convinced of their decision, although negative effects are more often reported by the patients than anticipated [40].

In contrast, for the subgroup of $B R C A 1$ and $B R C A 2$ mutation carriers, prophylactic bilateral mastectomy has to be discussed as a potential way to significantly reduce the immanent high life-time risk for developing breast cancer [44]. For patients who are already diagnosed with or have been treated for unilateral breast cancer and who were tested positive for a BRCA1 or BRCA2 mutation, a potential benefit of a bilateral mastectomy (if BCT is possible for the affected breast) or a CPM has not been clearly demonstrated so far: As we know, the rate of a second occurrence of ipsilateral metachronic breast cancer is not higher in comparison to non-mutation carriers [45]. Although the incidence of contralateral breast cancer can be reduced by a CPM, there are still insufficient followup data to postulate a positive impact on OS [46]. In this context, particularly the patient's age at first diagnosis has to be taken into consideration in order to maintain adequate counseling on the remaining life-time risk [47].

\section{Impacts in Counseling Patients in the Decision of BCT versus Mastectomy}

When discussing the options of mastectomy versus BCT with a patient in a primary breast cancer situation, we must first clarify several important points that are commonly misunderstood by newly diagnosed patients. Patients often have the impression that mastectomy is a safer approach in breast cancer treatment simply because it includes more extensive surgery. Similarly, patients often assume that mastectomy provides a guarantee that they will never have to deal with breast cancer again during their lifetime, or that undergoing a radical surgery approach could help them to avoid chemotherapy. These misperceptions are often not sufficiently verbalized so that it is necessary to clearly communicate the following facts concerning breast cancer surgery to the patient:

- The long-term OS is equivalent for BCT and mastectomy.

- The risk of LRR after BCT and mastectomy is similar on a very low level, with a slight trend in favor of mastectomy, especially for young breast cancer patients. Mastectomy does not completely eliminate the risk of local recurrence or a new primary cancer.

- Chemotherapy recommendations (whether adjuvant or neoadjuvant) are issued independently of the decision to pursue BCT versus mastectomy. A reasonable tumor response to neoadjuvant chemotherapy might otherwise enable a breast-conserving management when mastectomy was initially indicated due to a poor breast/tumor size relation and/or multicentric disease.

- Radiotherapy may still be indicated following mastectomy due to the interdependency of other factors (like axillary lymph node status).

Based on this information we must finally refer this decision of BCT versus mastectomy to the patient's personal responsibility, in the sense of an informed consent after a shared decision-making process. Obviously, there is no survival difference in the surgical approach when the performance of BCT seems possible. Breast conservation has advantages that fit to the preferences of most of the patients so that BCT is in general the preferred option. We know that, compared with mastectomy, BCT has advantages with regard to lower levels of psychological morbidity, less anxiety, and improved body image, sexuality and self-esteem [48], although other data could show that (immediate) reconstruction after mastectomy with good aesthetic outcome can maintain the quality of life comparable to the results seen after BCT $[49,50]$. Another advantage of BCT is that it may allow the patients to avoid axillary dissection if they had a positive lymph node status after sentinel node biopsy and if they are treated according to the ACOSOG Z0011 criteria [51]. More than two-thirds of all primary breast cancer patients are nowadays treated with breast conservation in a routine clinical setting in a specialized breast unit in developed countries [1].

Nonetheless, we must accept that patients' preferences might differ individually and that avoiding long-term local recurrence (even when the actual benefit due to this decision might be extremely small) or fear of a potential second surgery (in the R1 situation) or radiotherapy might be important individual motifs for some patients $[52,53]$. That is, in an individual hierarchy of priorities, some of these factors could be estimated higher than others, like aesthetic ones. Also the doctor's advice (which reflects the doctor's preference) is an important factor influencing the final treatment decision [54]. We should frankly communicate the fact that a 
slightly higher rate of local recurrence is still evident; i.e., in BCT patients, there is a lifelong consistent but small risk of locoregional relapse. In this context, it must be stated that also after mastectomy residual breast tissue remains in the breast in most patients [55]. Especially young patients need specific counseling. Late in-breast recurrences were more frequently observed in younger patients treated with BCT compared with those submitted to mastectomy $[56,57]$. The risk of an LRR after BCT is inversely proportional to age. Because of this, the largest absolute benefit of adjuvant therapy is observed in younger patients [58]. Notwithstanding this risk, no survival differences are seen in retrospective analyses comparing BCT and mastectomy [17]. Young age is not a contraindication against breast-conserving management, but the potential higher risk of LRR should be discussed with the patient. Particularly young women find decision-making challenging when the characteristics of their diagnosis provide an equal surgical choice between mastectomy and breast conservation [59]. BCT yields favorable outcomes for the large majority of patients, although increased LRR was observed among those with non-luminal A subtypes and increasing lymph node involvement [60]. Also the individual perceptions of contralateral breast cancer risk should be discussed [41]. As reconstruction options continue to improve, new techniques such as skin-sparing (with or without nipple-sparing) mastectomy with immediate reconstruction may lead to even higher rates of mastectomy in the future [61]. Irrespective of the final treatment recommendation, the patient's individual request should be accepted in every situation, also in case that the decision made by the patient does not seem rational under the perspective of recent evidence. Given that the recurrence rates are almost the same, the recall rates after BCT are now very low, and that studies show equal (or even better) survival rates for BCT in comparison to mastectomy, there is still a group of patients where performing mastectomy should be indicated. These hard indications for mastectomy include:

- When a sufficient aesthetic outcome with BCT is not feasible, a mastectomy with prior counseling of the patient on reconstruction can be necessary (i.e. in case of a multicentric/multifocal tumor), or when a general high risk for local recurrence can be assumed (i.e. an extensive ductal carcinoma in situ (DCIS) component/extensive or diffuse microcalcifications in the breast).

- When a R1 situation after 1 or 2 re-excision procedures persists, a mastectomy should be discussed. In general, tumor-free margins should be aspired after BCT [62].

- Any surgical situation that makes an adjuvant radiotherapy necessary when radiotherapy was already performed in the past (e.g. after BCT in the past or radiation in childhood due to lym- phoma). Recent data show that in some cases a second BCT in special breast cancer patients might be feasible [63].

\section{Summary and Future Aspects}

BCT has been established as the standard surgical procedure for primary breast cancer and fits to the preferences of most breast cancer patients concerning oncological safety and aesthetic outcome. When there is no specific contraindication against a breastconserving approach, BCT is as safe an option as mastectomy concerning overall long-term survival. For completeness, it must be stated that there is a lifelong consistent but small risk of in-breast relapse that is higher in BCT than in mastectomy. Especially the slightly higher risk of LRR after BCT in younger patients has to be mentioned and considered in the individual decision-making process with the patient when presenting BCT as a method that can be labeled as equally safe as mastectomy. The individual hierarchy of preferences driven by the avoidance of re-surgery or radiation, by aesthetic outcome or fear of relapse might differ between patients, but they all share the need for individual und substantial counseling concerning the pros and cons, which is a complex communication process [64]. In the context of counseling patients in an early breast cancer situation, a clear communication strategy on the principles of shared-decision making with regard to the surgical options is necessary [65]. It should be underlined that the treatment of breast cancer is made in a multidisciplinary setting where the surgical factor is just one aspect in the whole breast cancer treatment chain, and the other parts, i.e. (neo)adjuvant systemic therapy and radiotherapy, might be indicated irrespective of the recommended surgical approach. Especially the factor of the patient's awareness of breast cancer in general has led to an increase in prophylactic mastectomies in the last decade without sufficient proof of the benefit in oncologic survival, especially for patients outside of a confirmed genetic high-risk situation [66]. In the future, the focus should be on the patient's individual risk perception and on adequate communication strategies in routine patient-doctor interactions to meet the expectations of the patient as an equal, well-informed dialogue partner [67].

\section{Disclosure Statement}

There are no conflicts of interests (e.g., employment, consultancies, stock ownership, honoraria, paid expert testimony, patent applications/registrations, grants or other funding regarding this article) for any of the authors.

\section{References}

1 Hennigs A, Riedel F, Gondos A, Sinn P, Schirmacher P, Marmé F, Jäger D, Kauczor H-U, Stieber A, Lindel K, Debus J, Golatta M, Schütz F, Sohn C, Heil J, Schneeweiss A: Prognosis of breast cancer molecular subtypes in routine clinical care: a large prospective cohort study. BMC Cancer 2016;16:734.
2 Moossdorff M, van Roozendaal LM, Schipper RJ, Strobbe LJ, Voogd AC, Tjan-Heijnen VC, Smidt ML: Inconsistent selection and definition of local and regional endpoints in breast cancer research. Br J Surg 2014;101:1657-1665.
3 Gourgou-Bourgade S, Cameron D, Poortmans P, Asselain B, Azria D, Cardoso F, A'Hern R, Bliss J, Bogaerts J, Bonnefoi H, Brain E, Cardoso MJ, Chibaudel B, Coleman R, Cufer T, Dal Lago L, Dalenc F, De Azambuja E, Debled M, Delaloge S, Filleron T, Gligorov J, Gutowski M, Jacot W, Kirkove C, MacGrogan 
G, Michiels S, Negreiros I, Offersen BV, Penault Llorca F, Pruneri G, Roche H, Russell NS, Schmitt F, Servent V, Thurlimann B, Untch M, van der Hage JA, van Tienhoven G, Wildiers H, Yarnold J, Bonnetain F, Mathoulin-Pelissier S, Bellera C, Dabakuyo-Yonli TS: Guidelines for time-to-event end point definitions in breast cancer trials: results of the DATECAN initiative (Definition for the Assessment of Time-to-event Endpoints in CANcer trials). Ann Oncol 2015;26:873-879.

4 Curran D, van Dongen JP, Aaronson NK, Kiebert G, Fentiman IS, Mignolet F, Bartelink H: Quality of life of early-stage breast cancer patients treated with radical mastectomy or breast-conserving procedures: results of EORTC Trial 10801. The European Organization for Research and Treatment of Cancer (EORTC), Breast Cancer Co-operative Group (BCCG). Eur J Cancer 1998;34:307-314.

5 Chen CM, Cano SJ, Klassen AF, King T, McCarthy C, Cordeiro PG, Morrow M, Pusic AL: Measuring quality of life in oncologic breast surgery: a systematic review of patient-reported outcome measures. Breast J 2010; 16:587-597.

6 Fisher B, Redmond C, Poisson R, Margolese R, Wolmark N, Wickerham L, Fisher E, Deutsch M, Caplan R, Pilch Y, et al.: Eight-year results of a randomized clinical trial comparing total mastectomy and lumpectomy with or without irradiation in the treatment of breast cancer. N Engl J Med 1989;320:822-828.

7 Fisher B, Bauer M, Margolese R, Poisson R, Pilch Y, Redmond C, Fisher E, Wolmark N, Deutsch M, Montague E, et al.: Five-year results of a randomized clinical trial comparing total mastectomy and segmental mastectomy with or without radiation in the treatment of breast cancer. N Engl J Med 1985;312:665-673.

8 Veronesi U, Banfi A, Salvadori B, Luini A, Saccozzi R, Zucali R, Marubini E, Del Vecchio M, Boracchi P, Marchini S, et al.: Breast conservation is the treatmen of choice in small breast cancer: long-term results of a randomized trial. Eur J Cancer 1990;26:668-670.

9 Veronesi U, Saccozzi R, Del Vecchio M, Banfi A, Clemente C, De Lena M, Gallus G, Greco M, Luini A, Marubini E, Muscolino G, Rilke F, Salvadori B, Zecchini A, Zucali R: Comparing radical mastectomy with quadrantectomy, axillary dissection, and radiotherapy in patients with small cancers of the breast. N Engl J Med 1981;305:6-11.

10 Early Breast Cancer Trialists' Collaborative Group: Effects of radiotherapy and surgery in early breast cancer. An overview of the randomized trials. N Engl J Med 1995;333:1444-1455.

11 Morris AD, Morris RD, Wilson JF, White J, Steinberg S, Okunieff P, Arriagada R, Lê MG, Blichert-Toft M, van Dongen JA: Breast-conserving therapy vs mastectomy in early-stage breast cancer: a meta-analysis of 10-year survival. Cancer J Sci Am 1997;3:6-12.

12 Veronesi U, Cascinelli N, Mariani L, Greco M, Saccozzi R, Luini A, Aguilar M, Marubini E: Twenty-year follow-up of a randomized study comparing breastconserving surgery with radical mastectomy for early breast cancer. N Engl J Med 2002;347:1227-1232.

13 Fisher B, Anderson S, Bryant J, Margolese RG, Deutsch M, Fisher ER, Jeong JH, Wolmark N: Twenty-year follow-up of a randomized trial comparing total mastectomy, lumpectomy, and lumpectomy plus irradiation for the treatment of invasive breast cancer. N Engl J Med 2002;347:1233-1241.

14 Fortin A, Larochelle M, Laverdiere J, Lavertu S, Tremblay $\mathrm{D}$ : Local failure is responsible for the decrease in survival for patients with breast cancer treated with conservative surgery and postoperative radiotherapy. J Clin Oncol 1999;17:101-109.

15 Rutgers EJ: Quality control in the locoregional treatment of breast cancer. Eur J Cancer 2001;37:447-453.
16 van Dongen JA, Voogd AC, Fentiman IS, Legrand C, Sylvester RJ, Tong D, van der Schueren E, Helle PA, van Zijl K, Bartelink H: Long-term results of a randomized trial comparing breast-conserving therapy with mastectomy: European Organization for Research and Treatment of Cancer 10801 trial. J Natl Cancer Inst 2000;92:1143-1150.

17 Litiere S, Werutsky G, Fentiman IS, Rutgers E, Christiaens MR, Van Limbergen E, Baaijens MH, Bogaerts J, Bartelink H: Breast conserving therapy versus mastectomy for stage I-II breast cancer: 20 year follow-up of the EORTC 10801 phase 3 randomised trial. Lancet Oncol 2012;13:412-419.

18 Zumsteg ZS, Morrow M, Arnold B, Zheng J, Zhang Z, Robson M, Traina T, McCormick B, Powell S, Ho AY: Breast-conserving therapy achieves locoregional outcomes comparable to mastectomy in women with T12N0 triple-negative breast cancer. Ann Surg Oncol 2013;20:3469-3476

19 Mamtani A, Morrow M: Why are there so many mastectomies in the United States? Annu Rev Med 2017; 68:229-241.

20 Cancer Genome Atlas Network: Comprehensive molecular portraits of human breast tumours. Nature 2012;490:61-70.

21 Ellis MJ, Perou CM: The genomic landscape of breast cancer as a therapeutic roadmap. Cancer Discov 2013; 3:27-34.

22 Prat A, Perou CM: Deconstructing the molecular portraits of breast cancer. Mol Oncol 2011;5:5-23.

23 Weigelt B, Baehner FL, Reis-Filho JS: The contribution of gene expression profiling to breast cancer classification, prognostication and prediction: a retrospective of the last decade. J Pathol 2010;220:263-280.

24 Hennigs A, Riedel F, Marme F, Sinn P, Lindel K, Gondos A, Smetanay K, Golatta M, Sohn C, Schuetz F, Heil J, Schneeweiss A: Changes in chemotherapy usage and outcome of early breast cancer patients in the last decade. Breast Cancer Res Treat 2016;160:491-499.

25 von Minckwitz G, Untch M, Blohmer JU, Costa SD, Eidtmann H, Fasching PA, Gerber B, Eiermann W, Hilfrich J, Huober J, Jackisch C, Kaufmann M, Konecny GE, Denkert C, Nekljudova V, Mehta K, Loibl S: Definition and impact of pathologic complete response on prognosis after neoadjuvant chemotherapy in various intrinsic breast cancer subtypes. J Clin Oncol 2012;30:1796-1804.

26 van la Parra RFD, Kuerer HM: Selective elimination of breast cancer surgery in exceptional responders: historical perspective and current trials. Breast Cancer Res 2016;18:28

27 Lowery AJ, Kell MR, Glynn RW, Kerin MJ, Sweeney KJ: Locoregional recurrence after breast cancer surgery: a systematic review by receptor phenotype. Breast Cancer Res Treat 2012;133:831-841.

28 Cao JQ, Olson RA, Tyldesley SK: Comparison of recurrence and survival rates after breast-conserving therapy and mastectomy in young women with breast cancer. Curr Oncol 2013;20:e593-e601.

29 Maishman T, Cutress RI, Hernandez A, Gerty S, Copson ER, Durcan L, Eccles DM: Local recurrence and breast oncological surgery in young women with breast cancer: the POSH Observational Cohort Study. Ann Surg 2017;266:165-172.

30 Mansel RE, Fallowfield L, Kissin M, Goyal A, Newcombe RG, Dixon JM, Yiangou C, Horgan K, Bundred $\mathrm{N}$, Monypenny I, England D, Sibbering M, Abdullah TI, Barr L, Chetty U, Sinnett DH, Fleissig A, Clarke D, Ell PJ: Randomized multicenter trial of sentinel node biopsy versus standard axillary treatment in operable breast cancer: the ALMANAC Trial. J Natl Cancer Inst 2006;98:599-609.
31 Veronesi U, Paganelli G, Viale G, Luini A, Zurrida S, Galimberti V, Intra M, Veronesi P, Maisonneuve P, Gatti G, Mazzarol G, De Cicco C, Manfredi G, Fernandez JR: Sentinel-lymph-node biopsy as a staging procedure in breast cancer: update of a randomised controlled study. Lancet Oncol 2006;7:983-990.

32 Kreienberg R, Albert US, Follmann M, Kopp IB, Kuhn T, Wockel A: Interdisciplinary GoR level III guidelines for the diagnosis, therapy and follow-up care of breast cancer: short version - AWMF Registry No.: 032045OL AWMF-Register-Nummer: 032-045OL - Kurzversion 3.0, Juli 2012. Geburtshilfe Frauenheilkd 2013 73:556-583.

33 D'Angelo-Donovan DD, Dickson-Witmer D, Petrell NJ: Sentinel lymph node biopsy in breast cancer: a history and current clinical recommendations. Surg Oncol 2012;21:196-200.

34 Giuliano AE, Ballman KV, McCall L, Beitsch PD, Brennan MB, Kelemen PR, Ollila DW, Hansen NM, Whitworth PW, Blumencranz PW, Leitch AM, Saha S, Hunt KK, Morrow M: Effect of axillary dissection vs no axillary dissection on 10-year overall survival among women with invasive breast cancer and sentinel node metastasis: the ACOSOG Z0011 (Alliance) randomized clinical trial. JAMA 2017;318:918-926.

35 Donker M, van Tienhoven G, Straver ME, Meijnen P, van de Velde CJ, Mansel RE, Cataliotti L, Westenberg AH, Klinkenbijl JH, Orzalesi L, Bouma WH, van der Mijle HC, Nieuwenhuijzen GA, Veltkamp SC, Slaets L, Duez NJ, de Graaf PW, van Dalen T, Marinelli A, Rijna H, Snoj M, Bundred NJ, Merkus JW, Belkacem Y, Petignat P, Schinagl DA, Coens C, Messina CG, Bogaerts J, Rutgers EJ: Radiotherapy or surgery of the axilla after a positive sentinel node in breast cancer (EORTC 10981-22023 AMAROS): a randomised, multicentre, open-label, phase 3 non-inferiority trial. Lancet Oncol 2014;15:1303-1310.

36 Chang JM, Kosiorek HE, Dueck AC, Casey WJ, Rebecca AM, Mahabir R, Patel SH, Keole SR, Wong WW Vargas CE, Halyard MY, Gray RJ, Wasif N, Stucky CH, Pockaj BA: Trends in mastectomy and reconstruction for breast cancer; a twelve year experience from a tertiary care center. Am J Surg 2016;212:1201-1210.

37 McGuire K, Santillan A, Kaur P, Meade T, Parbhoo J, Mathias M, Shamehdi C, Davis M, Ramos D, Cox C: Are mastectomies on the rise? A 13-year trend analysis of the selection of mastectomy versus breast conservation therapy in 5865 patients. Ann Surg Oncol 2009; 16:2682-2690.

38 Garcia-Etienne CA, Tomatis M, Heil J, Friedrichs K, Kreienberg R, Denk A, Kiechle M, Lorenz-Salehi F, Kimmig R, Emons G, Danaei M, Heyl V, Heindrichs U, Rageth CJ, Janni W, Marotti L, del Turco MR, Ponti A: Mastectomy trends for early-stage breast cancer: a report from the EUSOMA multi-institutional European database. Eur J Cancer 2012;48:1947-1956.

39 Albornoz CR, Matros E, Lee CN, Hudis CA, Pusic AL, Elkin E, Bach PB, Cordeiro PG, Morrow M: Bilateral mastectomy versus breast-conserving surgery for early-stage breast cancer: the role of breast reconstruction. Plast Reconstr Surg 2015;135:1518-1526.

40 Rosenberg SM, Tracy MS, Meyer ME, Sepucha K, Gelber S, Hirshfield-Bartek J, Troyan S, Morrow M, Schapira L, Come SE, Winer EP, Partridge AH: Perceptions, knowledge, and satisfaction with contralateral prophylactic mastectomy among young women with breast cancer: a cross-sectional survey. Ann Intern Med 2013;159:373-381.

41 Portschy PR, Abbott AM, Burke EE, Nzara R, Marmor S, Kuntz KM, Tuttle TM: Perceptions of contralateral breast cancer risk: a prospective, longitudinal study. Ann Surg Oncol 2015;22:3846-3852. 
42 Wong SM, Freedman RA, Sagara Y, Aydogan F, Barry WT, Golshan M: Growing use of contralateral prophylactic mastectomy despite no improvement in long-term survival for invasive breast cancer. Ann Surg 2017;265: 581-589.

43 Kurian AW, Lichtensztajn DY, Keegan TH, Nelson DO Clarke CA, Gomez SL: Use of and mortality after bilateral mastectomy compared with other surgical treatments for breast cancer in California, 1998-2011. JAMA 2014;312:902-914.

44 Li X, You R, Wang X, Liu C, Xu Z, Zhou J, Yu B, Xu T, Cai $\mathrm{H}$, Zou Q: Effectiveness of prophylactic surgeries in BRCA1 or BRCA2 mutation carriers: a meta-analysis and systematic review. Clin Cancer Res 2016;22: 3971-3981.

45 Robson M, Svahn T, McCormick B, Borgen P, Hudis CA, Norton L, Offit K: Appropriateness of breast-conserving treatment of breast carcinoma in women with germline mutations in BRCA1 or BRCA2: a clinicbased series. Cancer 2005; 103:44-51.

46 Heemskerk-Gerritsen BA, Rookus MA, Aalfs CM, Ausems MG, Collee JM, Jansen L, Kets CM, Keymeulen KB, Koppert LB, Meijers-Heijboer HE, Mooij TM, Tollenaar RA, Vasen HF, Hooning MJ, Seynaeve C: Improved overall survival after contralateral riskreducing mastectomy in $B R C A 1 / 2$ mutation carriers with a history of unilateral breast cancer: a prospective analysis. Int J Cancer 2015;136:668-677.

47 Graeser MK, Engel C, Rhiem K, Gadzicki D, Bick U, Kast K, Froster UG, Schlehe B, Bechtold A, Arnold N, Preisler-Adams S, Nestle-Kraemling C, Zaino M, Loeffler M, Kiechle M, Meindl A, Varga D, Schmutzler RK: Contralateral breast cancer risk in BRCA1 and BRCA2 mutation carriers. J Clin Oncol 2009;27:58875892.

48 Al-Ghazal SK, Fallowfield L, Blamey RW: Comparison of psychological aspects and patient satisfaction following breast conserving surgery, simple mastectomy and breast reconstruction. Eur J Cancer 2000;36:19381943.

49 Howes BH, Watson DI, Xu C, Fosh B, Canepa M, Dean NR: Quality of life following total mastectomy with and without reconstruction versus breast-conserving surgery for breast cancer: a case-controlled cohort study. J Plast Reconstr Aesthet Surg 2016;69: 1184-1191.
50 Kim MK, Kim T, Moon HG, Jin US, Kim K, Kim J, Lee JW, Kim J, Lee E, Yoo TK, Noh DY, Minn KW, Han W: Effect of cosmetic outcome on quality of life after breast cancer surgery. Eur J Surg Oncol 2015;41: 426-432.

51 Giuliano AE, Hunt KK, Ballman KV, et al.: Axillary dissection vs no axillary dissection in women with invasive breast cancer and sentinel node metastasis: a randomized clinical trial. JAMA 2011;305:569-575.

52 Katz SJ, Lantz PM, Janz NK, Fagerlin A, Schwartz K, Liu L, Deapen D, Salem B, Lakhani I, Morrow M: Patient involvement in surgery treatment decisions for breast cancer. J Clin Oncol 2005;23:5526-5533.

53 Covelli AM, Baxter NN, Fitch MI, McCready DR, Wright FC: 'Taking control of cancer': understanding women's choice for mastectomy. Ann Surg Oncol 2015;22:383-391.

54 Morrow M, Jagsi R, Alderman AK, Griggs JJ, Hawley ST, Hamilton AS, Graff JJ, Katz SJ: Surgeon recommendations and receipt of mastectomy for treatment of breast cancer. JAMA 2009;302:1551-1556.

55 Griepsma M, de Roy van Zuidewijn DB, Grond AJ, Siesling S, Groen H, de Bock GH: Residual breast tissue after mastectomy: how often and where is it located? Ann Surg Oncol 2014;21:1260-1266.

56 Arriagada R, Lê MG, Guinebretiere JM, Dunant A, Rochard F, Tursz T: Late local recurrences in a randomised trial comparing conservative treatment with total mastectomy in early breast cancer patients. Ann Oncol 2003;14:1617-1622.

57 van der Sangen MJ, van de Wiel FM, Poortmans PM, Tjan-Heijnen VC, Nieuwenhuijzen GA, Roumen RM, Ernst MF, Tutein Nolthenius-Puylaert MC, Voogd AC: Are breast conservation and mastectomy equally effective in the treatment of young women with early breast cancer? Long-term results of a population-based cohort of 1,451 patients aged $\leq 40$ years. Breast Cancer Res Treat 2011;127:207-215.

58 Bartelink H, Horiot JC, Poortmans PM, Struikmans H, Van den Bogaert W, Fourquet A, Jager JJ, Hoogenraad WJ, Oei SB, Warlam-Rodenhuis CC, Pierart M, Collette L: Impact of a higher radiation dose on local control and survival in breast-conserving therapy of early breast cancer: 10-year results of the randomized boost versus no boost EORTC 22881-10882 trial. J Clin Oncol 2007;25:3259-3265.
59 Recio-Saucedo A, Gerty S, Foster C, Eccles D, Cutress RI: Information requirements of young women with breast cancer treated with mastectomy or breast conserving surgery: a systematic review. Breast 2016;25: $1-13$.

60 Braunstein LZ, Taghian AG, Niemierko A, Salama L, Capuco A, Bellon JR, Wong JS, Punglia RS, MacDonald SM, Harris JR: Breast-cancer subtype, age, and lymph node status as predictors of local recurrence following breast-conserving therapy. Breast Cancer Res Treat 2017;161:173-179.

61 Throckmorton AD, Esserman LJ: When informed, all women do not prefer breast conservation. J Clin Oncol 2009;27:484-486.

62 Houssami N, Macaskill P, Marinovich ML, Dixon JM Irwig L, Brennan ME, Solin LJ: Meta-analysis of the impact of surgical margins on local recurrence in women with early-stage invasive breast cancer treated with breast-conserving therapy. Eur J Cancer 2010;46: 3219-3232.

63 Kolben T, Schwarz TM, Goess C, Blume C, Degenhardt T, Engel J, Wuerstlein R, Ditsch N, Harbeck N Kahlert S: Surgical management of ipsilateral breast tumor recurrence. Int J Surg 2015;23:141-146.

64 Katz SJ, Morrow M: The challenge of individualizing treatments for patients with breast cancer. JAMA 2012; 307:1379-1380.

65 Bieber C, Nicolai J, Gschwendtner K, Muller N, Reuter K, Buchholz A, Kallinowski B, Harter M, Eich W: How does a shared decision-making (SDM) intervention for oncologists affect participation style and preference matching in patients with breast and colon cancer? J Cancer Educ 2016, in press. DOI: 10.1007/s13187016-1146-7

66 Lostumbo L, Carbine NE, Wallace J: Prophylactic mastectomy for the prevention of breast cancer. Cochrane Database Syst Rev 2010;(11):CD002748.

67 Schmidt H, Cohen A, Mandeli J, Weltz C, Port ER Decision-making in breast cancer surgery: where do patients go for information? Am Surg 2016;82:397402 